\title{
Products eco-sustainability analysis using CAD SolidWorks software
}

\author{
Luminița I. Popa ${ }^{1, *}$, and Vasile N. Popa ${ }^{2}$ \\ ${ }^{1}$ Transilvania University of Braşov,Department of Automation and Information Technologies, Mihai \\ Viteazul 5, Braşov, Romania \\ ${ }^{2}$ Regional Department for Defense Resources Management Studie s, Mihai Viteazul 130, Braşov, \\ Romania
}

\begin{abstract}
This article is focused on the analysis of environmental impact and Eco-sustainability of models designed using CAD SolidWorks software. We have evaluated the material it was made the whole ansamble, in terms of strength, durability and environmental pollution considering the carbon footprint, energy consumption, air acidification and eutrophication. We considered the whole product life-cycle management, from raw material extraction, processing it, piece production, assembly it, and use it until the end of his life, considering the mode of transport and the distance between these stages. The case study presents the virtual model of the product and Sustainability Report.
\end{abstract}

\section{The concept of sustainability}

The sustainability definition is the one proposed in 1987 by the Commission for Environment and Development (known as the Brundtland Report), according to: "the sustainable development is the type of economic development that meets the needs of present generations without compromising the ability of future generations to meet their own needs".

One of the major challenges of sustainable development is to find ways to encourage environmentally friendly economic activities and discourage those causing damage to the environment (air, water and soil or subsoil).

\section{Sustainable design}

Behind the sustainable design concept there is a whole philosophy of economic, social and environmental responsibility that should follow each corporation, company, organization, agency or state institution.

Sustainable design must consider the environment and natural resources, which are accessible to the community, protecting the environment from the negative effects of production activities and using resources with responsibly.

* Corresponding author: mluminita2001@yahoo.com 
Sustainable design looks at how your product's development, from cradle to grave, will affect four crucial environmental factors: air acidification; carbon footprint; total energy consumed; and water eutrophication. Measuring these impacts will help you better design for the environment.

\subsection{Lifecycle analysis}

Definition of lifecycle analysis is emerging from the content of ISO 14040 and aims to achieve the following goals: composition of a record with relevant inputs and outputs of the system; evaluating the potential environmental impacts associated with these inputs and outputs; interpretation of record results and impact phases in relation to the study objectives. There are three major components of the Lifecycle Analysis: analyzing evidence, assessing the impact and assess possible improvements.

LCA addresses the overall impact on the environment associated with the production, use and disposal of materials and identifies the key indicators of environmental pollution sources.

\subsubsection{Environmental impact}

Environmental impact includes expedition and use of limited natural resources, atmosphere, land and water pollution, environmental quality, ecosystem health and human health, as well as evaluating safety problems at every stage of the production cycle. An example of this is the Eco Index industry model, created by the collaborative efforts of over 100 producers and retailers and coordinated by the Outdoor Industry Association. The result of this model is a software application that guides its users through a series of questions for each of the six life cycle stages with seven key areas of impact. (Table 1)

Table 1. Eco Index industry model (made by the authors).

\begin{tabular}{|c|c|c|c|c|c|c|c|c|}
\hline \multirow{4}{*}{\multicolumn{2}{|c|}{$\begin{array}{l} \\
\text { STAGES/ } \\
\text { IMPACTS }\end{array}$}} & \multicolumn{5}{|c|}{ Before customer } & \multicolumn{2}{|c|}{ Customer } \\
\hline & & \multirow{2}{*}{\multicolumn{2}{|c|}{ 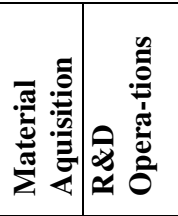 }} & \multicolumn{3}{|c|}{ Manufacturig Operations } & \multirow{3}{*}{ 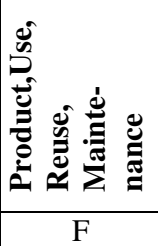 } & \multirow[b]{2}{*}{ 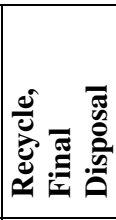 } \\
\hline & & & & \multirow{2}{*}{ 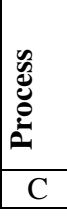 } & \multirow{2}{*}{ 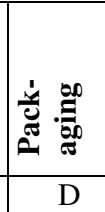 } & \multirow{2}{*}{ 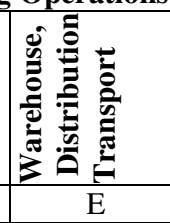 } & & \\
\hline & & A & $\mathrm{B}$ & & & & & \\
\hline \multicolumn{9}{|c|}{ ENVIRONMENT } \\
\hline Air & 1 & & & & & & & \\
\hline Water & 2 & & & & & & & \\
\hline Solid Waste & 3 & & & & & & & \\
\hline ENERGY & 4 & & & & & & & \\
\hline \begin{tabular}{|l|} 
RESOURCE \\
USE
\end{tabular} & 5 & & & & & & & \\
\hline \multicolumn{9}{|l|}{ HEALTH } \\
\hline Chemical & 6 & & & & & & & \\
\hline Physical & 7 & & & & & & & \\
\hline Biological & 8 & & & & & & & \\
\hline \multicolumn{9}{|l|}{ SAFETY } \\
\hline Chemical & 9 & & & & & & & \\
\hline Electrical & 10 & & & & & & & \\
\hline Mechanical & 11 & & & & & & & \\
\hline
\end{tabular}




\subsubsection{The 5-Pillar Method}

The 5-pillar methodology involves the evaluation of a novel chemical process and comparison to another comparable one (same functionally for final product) based on a set of key parameters [1- 4].These five parameters represent the technical performance of a scaled-up process, economic feasibility, environmental impact, human health, and systemic risks. For this method, the parameters that contribute to the final score, are shown in Table 2:

Table 2. Overview of 5-pillar assessment method.

\begin{tabular}{|c|c|c|c|c|c|}
\hline Innovativ & new process & & nventional proc & & 预 \\
\hline 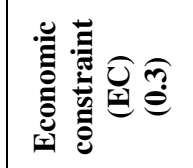 & 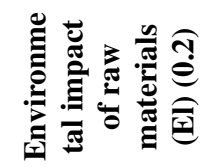 & 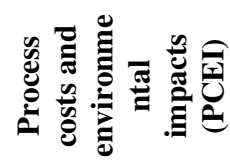 & 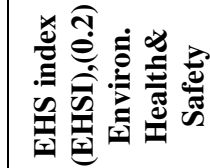 & 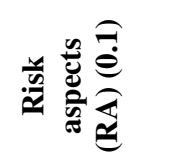 & 1,00 \\
\hline Price ratio & $\begin{array}{l}\text { Cumulative } \\
\text { energy demand }\end{array}$ & $\begin{array}{l}\text { Energy loss } \\
\text { Index }\end{array}$ & Environment & $\begin{array}{l}\text { Feedstock } \\
\text { supply risk }\end{array}$ & \\
\hline $\begin{array}{l}\text { Practical } \\
\text { yields }\end{array}$ & $\begin{array}{l}\text { GHG (Green- } \\
\text { house Gas) } \\
\text { emissions }\end{array}$ & $\begin{array}{l}\text { Product } \\
\text { concentration }\end{array}$ & Persistency & Market risk & \\
\hline $\begin{array}{l}\text { Allocated } \\
\text { raw material } \\
\text { costs }\end{array}$ & & Water content & Air hazard & $\begin{array}{l}\text { Infrastructura } \\
\text { (availability) } \\
\text { risk }\end{array}$ & \\
\hline Market price & & $\begin{array}{l}\text { Boiling point } \\
\text { difference }\end{array}$ & Water hazard & $\begin{array}{l}\text { Regional } \\
\text { feedstock } \\
\text { availability }\end{array}$ & \\
\hline & & Mass loss index & Solid waste & $\begin{array}{l}\text { Application- } \\
\text { technical } \\
\text { aspects }\end{array}$ & \\
\hline & & Reaction energy & Health & & \\
\hline & & No. of coproducts & Irritation & & \\
\hline & & Pretreatment & Chronic toxicity & & \\
\hline & & & Safety & & \\
\hline & & & Mobility & & \\
\hline & & & Fire/explosion & & \\
\hline & & & Reactivity & & \\
\hline & & & Acute toxicity & & \\
\hline
\end{tabular}

\section{Products eco-sustainability analysis using CAD SolidWorks software}

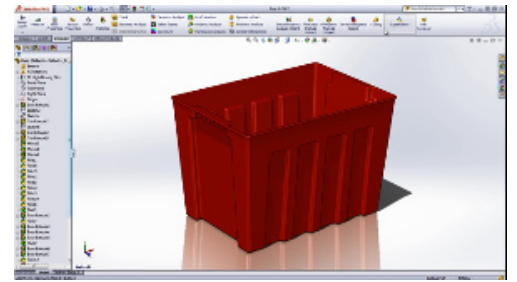

Fig. 1.The virtual model of plastic storage box. 
Once completed the plastic box modeling, we will start the product sustainability study using the "Sustainability" menu (Figure 1). By accessing the "Set Material" tab, was launched the plastics materials database available. (Figure 2). Figure 2 is a database that contains class plastics, "Material Class". In the fields from the table head are shown the characteristics of each material (Specific Heat, Mass density, etc.).

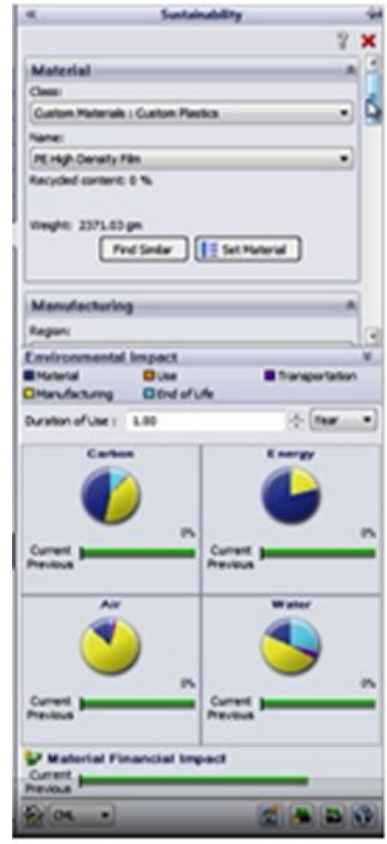

Fig. 1. The product,

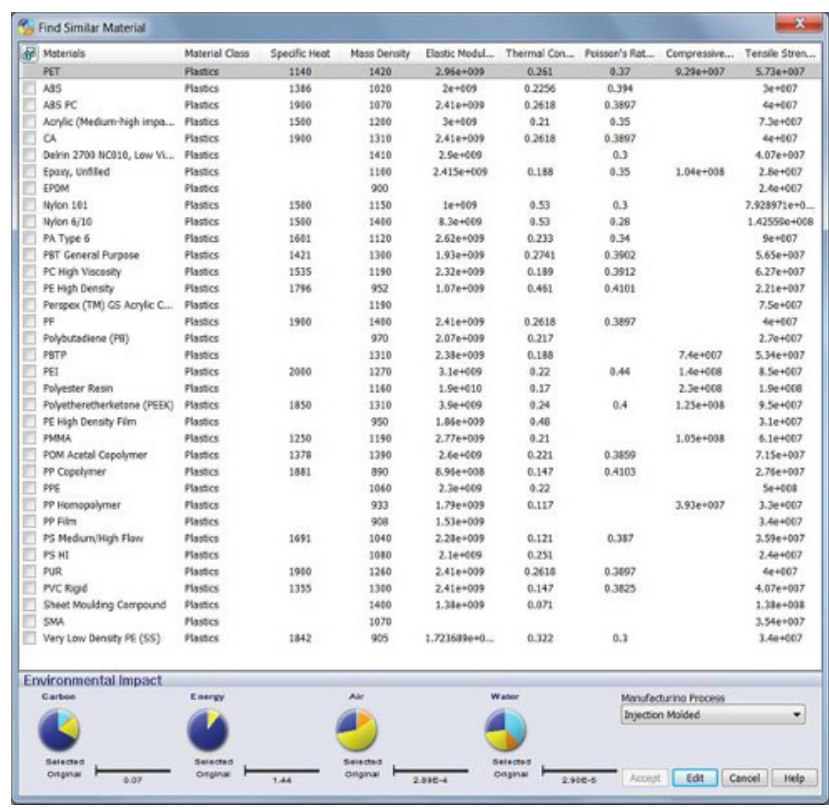

Fig. 2.The plastics materials database.

"Sustainability" menu.

From the plastics database is chosen the material with "High Density PE", as indicated in Figure 1.

We use the world map is in this menu in order to choose where the product will be transported after production. The greater is the distance between the manufacturer and the user, the less ecological is the product.In this case, the final use of the product will be in North America (Figure 3) .

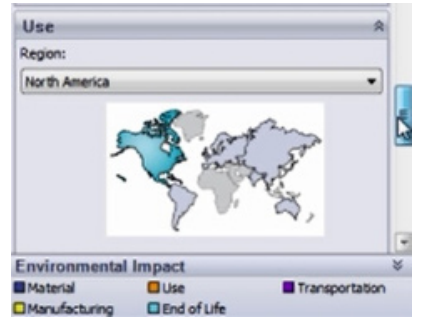

Fig. 3. User Menu.

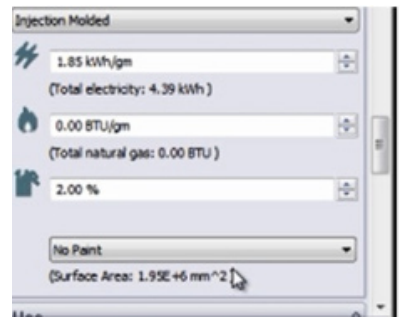

Fig. 4. Injection Molded Tab.

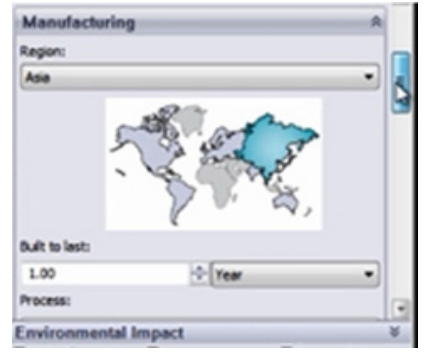

Fig. 5. Manufacturing Tab. 
In the "Manufacturing" process, it was chosen, as the manufacturing technology, the injection molded process "Injection Molded" (Figure 4). In Figure5 is represented the manufacturing location -Asia. .Also, it was initially opted for option "No paint". In these conditions, environmental impact factors, are represented in Figure 6.

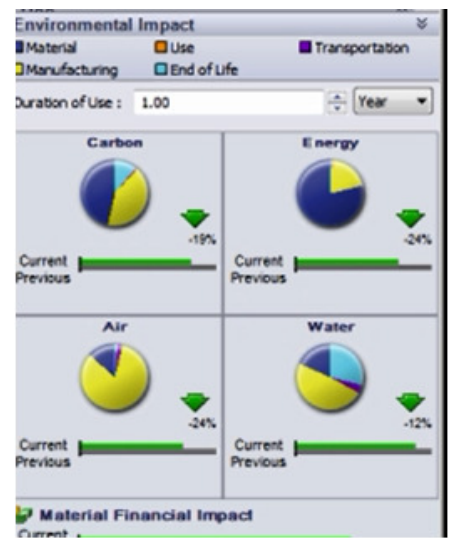

Fig. 6. Menu Environmantal Impact.
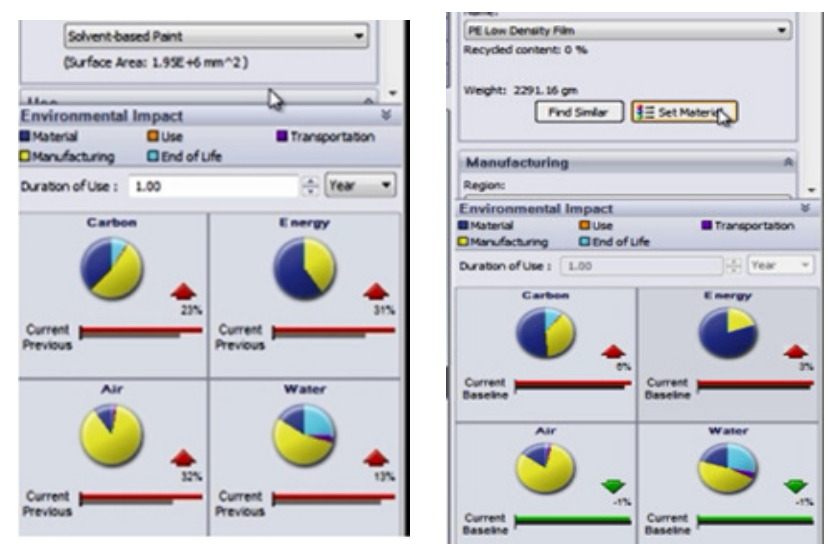

Fig. 7. Injection Molded Paint. Fig. 8. Set material PE Low.

If was chosen the mold painting mode, in Figure 7 a can be seen the environmental indicators modification.If was chosen material change ("PE Low density Film"), this choice can be seen as another environmental indicators modification (Figure 8). Similar material PE Low could be seen in Figure 9.

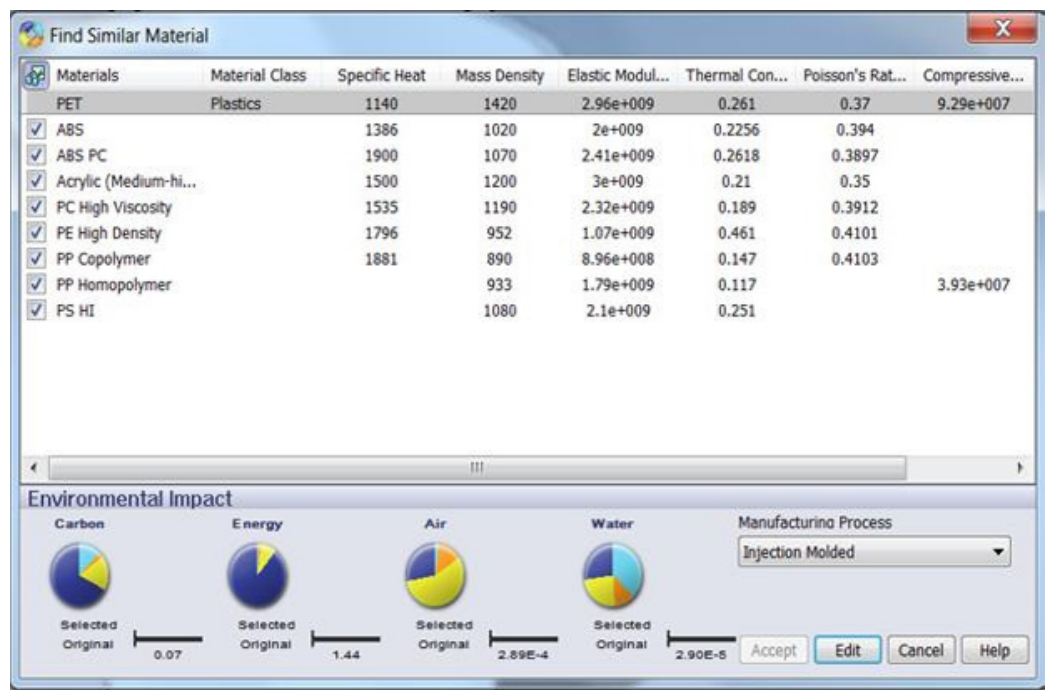

Fig. 9. Find similar material PE Low.

It was generated the Sustainability Report. The outcome is presented in Figure 10. 

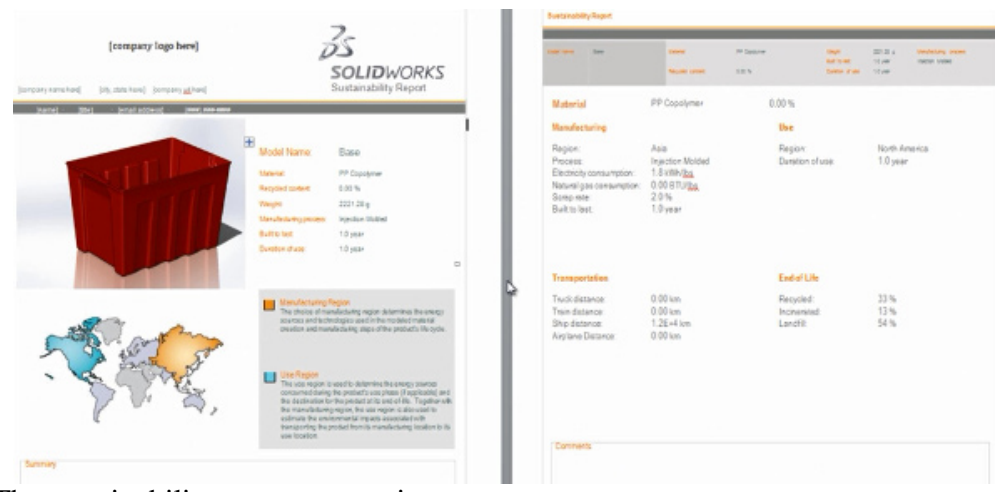

Fig.10. The sustainability report generation.

\section{Conclusions}

EcoDesign guidelines are a set of best design practices and represent a database of ecological questions and relative answers using a set of well-known standard design parameters [2]. The raw material and environmental impacts emissions (in the case of GHG, Table 2), are associated with bioethanol as a range of different values that can be found in literature [3]. Environmental indicators have become objective functions or constraints in the LCA models. LCA methodologies are becoming quite common because they allow both retrospective and prospective assessment of the environmental impact of a certain product or process (taking into account its entire life cycle) [4]. Solidworks Sustainability provides real-time feedback on environmental impact factors.

The results appear in the Environmental Impact Menu and could be updated dynamically with any changes. Solidworks Sustainability is useful to compare with experimental results or for better sustainability of designed products. Reducing the used material is made by optimizing the design full power. The less material is used for a product, the less resources are used in the production process.

\section{References}

1. A. D. Patel, J. A.Posada, L. Shen and M. K. Patel, Early $R \& D$ Stage Sustainability Assessment:The 5-Pillar Method,Wiley Series in Renewable resources, John Wiley\&Sons, Ltd., (2016)

2. F. Cappelli, M. Delogu, M. Pierini, Proceedings of LCE (2006) http://citeseerx.ist.psu.edu/viewdoc/download?doi=10.1.1.128.9866\&rep=rep1\&type= pdf, accessed 13.01.2017

3. A. D. Patel, et al, ESI or Energy \& Environmental Science,(2012) http://www.rsc.org/suppdata/ee/c2/c2ee21581k/c2ee21581k.pdf, , accessed 12.07.2017

4. Sustainability of Products, Processes and Supply Chains Theory and Applications, 36, 1st Edition, Elsevier (2015) https://www.elsevier.com/books/sustainability-ofproducts-processes-and-supply-chains-theory-and-applications/you/978-0-444-63472$\underline{6}$, accessed 11.01.2017 